\title{
RESILIENCIA LABORAL JUVENIL EN TIEMPOS DE PANDEMIA
}

\section{Youth work resilience in times of pandemic}

\author{
Gloria Melina Leyva Tarazona ${ }^{8}$ \\ Ketty Marilú Moscoso Paucarchuco \\ Cristian Jordy Casas Cornelio \\ Reysenia Peña Chinguel \\ Claudia Adelayda Quispe Santos \\ Anali Karin Sillo Campos \\ Kelvin Jhon Ramirez Palomino \\ Universidad Roosevelt, Perú
}

\section{RESUMEN}

Esta revisión bibliográfica resume una selección curada de resultados disponibles de la investigación sobre los jóvenes y el trabajo juvenil en el contexto de la pandemia de COVID-19 y la estrecha relación con el Objetivo de Desarrollo Sostenible 8, en su numeral 8.6, que busca al 2020 reducir el desempleo en jóvenes con una oportunidad de trabajo decente. El objetivo es comprender la diversidad de formas en que los jóvenes se ven afectados por esta causa de fuerza mayor, identificar recomendaciones clave para la política de la juventud y proporcionar métodos y técnicas que ha adoptado el trabajo juvenil, contribuyendo así al buen desenvolvimiento de la juventud en tiempos inciertos.

Dada la evolución rápida de la pandemia, muchas de las investigaciones actualmente están en curso, por lo que la revisión de

${ }^{8}$ Representante del Grupo de PSEU “Sostenibilidad Empresarial” integrado por estudiantes de la carrera profesional de Administración y Negocios Internacionales de la Universidad Roosevelt. Registro ORCID https://orcid.org/0000-0002-3028-5452, correspondencia a melinaaLT06@gmail.com 
la literatura solo puede ser visto como un panorama en constante crecimiento y cambio; en muchos casos, solo se dispone de datos preliminares o de la primera ola. En consecuencia, es motivo para continuar modificando, ampliando y desarrollando esta revisión en los próximos meses. La tendencia general enfatiza las crecientes disparidades entre las reacciones de la sociedad en general y los jóvenes en respuesta a las medidas de contención, centrándose en la socialización y sobretodo el empleo.

Las recomendaciones clave que surgen de la necesidad de reconocer el enorme precio que la pandemia ha ocasionado en los jóvenes, no garantiza la financiación y el apoyo adecuados a través de políticas de juventud, urge una toma de decisiones acertada para el proceso de recuperación, así como desarrollar soluciones innovadoras que aseguren el trabajo juvenil, logrando cumplir su función como servicio esencial y derecho fundamental.

\section{INTRODUCCIÓN}

El trabajo de los jóvenes y el trabajo desde casa, son dos cosas que nunca se habrían reunido. Sin embargo, aquí es donde nosotros, y muchos otros en el mismo campo, nos encontramos actualmente. Muchos eligieron una profesión que está muy orientada a las personas, que requiere mucho cuidado, compasión, empatía, paciencia y energía. Ciertamente no es un rol que asociaría con la soledad, pero estos son algunos de los pensamientos y sentimientos que se ha experimentado desde la perspectiva juvenil durante el encierro. Sabemos que no somos los únicos que nos hemos sentido así, todos luchamos por ser resistentes y flexibles en la forma en que trabajamos (Dicken, 2020).

El nuevo coronavirus o SARS-CoV-2, se ha apoderado del mundo con fuerza en la primera mitad de 2020 y continúa con sus estragos. El mundo atraviesa una época sin precedentes: la pandemia de coronavirus ha tomado por sorpresa a personas, gobiernos $\mathrm{y}$ sociedades, y el trabajo con jóvenes no es excepción. Algunas de las 
consecuencias inmediatas de la pandemia y las respuestas estratégicas en el ámbito político, han ocasionado de manera intermitente mayor visibilidad en el empleo juvenil, generando impacto a largo plazo y los efectos en las diferentes regiones del país que siguen sin estar claras. Es primordial evaluar adecuadamente estas circunstancias extraordinarias, que emergen de un débil impulso y reinvención laborar endeble, con el fin de trazar nuevos caminos para la juventud.

Los Objetivos de Desarrollo Sostenible (ODS), en especial el objetivo 8, planteados en la Agenda 2030 (Naciones Unidas/CEPAL, 2019) donde se busca "promover el crecimiento económico sostenido, inclusivo y sostenible, el empleo pleno y productivo y el trabajo decente para todos", y su numeral 8.6 donde se plantea "De aquí a 2020, reducir considerablemente la proporción de jóvenes que no están empleados y no cursan estudios ni reciben capacitación", es una herramienta prospectiva, que muestra indicios de deficiencia en estas circunstancias de pandemia.

\section{TRABAJO JUVENIL ANTES Y DURANTE LA PANDEMIA EN EL PERÚ Y EL MUNDO}

Las pandemias no son una ocurrencia nueva, sin embargo, es de destacar el cambio en mortalidad y morbilidad a los grupos de edad más jóvenes, a pesar de la prevalencia de las pandemias y el aumento potencial de la susceptibilidad de los jóvenes, las investigaciones o estudios previos sobre el efecto de las pandemias específicamente en los jóvenes o el trabajo juvenil no son comunes. Sugieren que los desastres pandémicos son únicos y no incluyen congregar sitios para apoyo y recuperación prolongados, requieren estrategias de respuesta para garantizar las necesidades de salud conductual de los niños y familias. La planificación para una pandemia debe abordar estas necesidades y las medidas de contención de enfermedades (Ginny Sprang, 2013). 
Los hallazgos más notables de Sprang y Silman (2013) destacan la ansiedad y el miedo que enfrentan los jóvenes y los niños a raíz de tanta incertidumbre generada por la pandemia, podría haber efectos duraderos en términos de desarrollo de trastorno de estrés postraumático. Teniendo esto en cuenta, hay una necesidad de incluir a jóvenes y niños en el desarrollo de respuestas pandémicas, ya que las pandemias continúan afectándolos de manera desproporcionada.

La contribución de la juventud al desarrollo de las comunidades locales ha sido un activo bien conservado en todas las naciones del mundo. Sin embargo, el apoyo brindado a esta categoría de personas y el potencial de las mismas no se ha explotado al máximo. El trabajo es una profesión antigua pero la profesionalización es todavía un concepto nuevo, en continua construcción, parte del rápido desarrollo de la juventud, del trabajo impactante, son ellos el pilar de la sociedad.

Considerada más bien como un período de transición, la palabra "juventud" no significa ni niños ni personas adultas, sino los jóvenes, generalmente de entre 13 y 30 años. Los años exactos (límites de edad) son difíciles de establecer y difieren de una región o país a otro, ya que no existe una frontera real o natural basada en la cual una persona llega a la edad de un niño, pero se convierte en un joven para el próximo cumpleaños. Si existe un período de transición entre la niñez y la adultez, generalmente se sitúa entre el período de salida de la escuela obligatoria y la obtención del primer empleo. Esta es la edad en la que la persona que se encuentra en el "período de transición" se explora a sí misma, brindando trabajo a la comunidad y el mundo en el que vive, busca desarrollar u obtener una serie de competencias y habilidades para la vida, especialmente habilidades para la vida independiente, que usará en el futuro a partir de los conocimientos y competencias desarrollados o adquiridos, el joven será capaz de tomar decisiones fundamentales, arraigadas en un conocimiento personal y general, dado que comprenderá la reacción de cada acción, 
eventualmente, basándose en los conocimientos adquiridos, podrá apuntar lejos hacia un destino que comprenda.

El cierre de escuelas y universidades ha afectado a más de 1.500 millones de niños y jóvenes en todo el mundo y ha cambiado significativamente la forma en que los jóvenes y los niños viven y aprenden durante la pandemia (Nations, 2020a), algunas de las herramientas innovadoras de enseñanza y aprendizaje y los sistemas de prestación con los que las escuelas y los profesores experimentaron en respuesta a la crisis pueden tener un impacto duradero en los sistemas educativos. Por otro lado, la evidencia de la OCDE muestra que cada semana de cierre de escuelas implica una pérdida en el desarrollo del capital humano con importantes implicaciones económicas y sociales a largo plazo.

A pesar de la flexibilidad y el compromiso demostrado por las escuelas y los maestros para asegurar la continuidad educativa durante el cierre, no todos los estudiantes han podido acceder a la educación de manera constante. Un estudio en 59 países demuestra que, aunque la mayoría de los países implementaron oportunidades de aprendizaje alternativas, casi la mitad de los estudiantes pudieron acceder a todo o la mayor parte del plan de estudios. Es probable que la pérdida de aprendizaje que ha ocurrido tenga un costo económico en las sociedades en forma de disminución de la productividad y el crecimiento. Las estimaciones muestran que un año escolar perdido puede considerarse equivalente a una pérdida de entre el $7 \%$ y el $10 \%$ de los ingresos de toda la vida (OECD, 2020).

En el contexto del cierre de escuelas, la calidad del entorno de aprendizaje en el hogar se vuelve aún más importante. Una brecha digital en la conectividad y el acceso a dispositivos electrónicos corre el riesgo de agravar aún más las desigualdades entre los jóvenes durante la pandemia. Por ejemplo, es menos probable que los estudiantes de familias menos acomodadas tengan acceso a recursos 
de aprendizaje digital y apoyo de los padres para el aprendizaje en el hogar.

La mayoría de los países de América Latina y el Caribe se ven afectados por altos niveles de desempleo juvenil y/o informalidad laboral (BID, 2013). En el caso de Perú, la informalidad es el más grave de estos problemas. Alrededor del $9 \%$ de los jóvenes entre 15 y 24 años están desempleados y el $80 \%$ de los jóvenes que están empleados tienen trabajos informales (Verónica Alaimo, AlvaroAltamirano, Daniela Dborkin, 2018). Para mejorar las condiciones del mercado laboral de los jóvenes, los gobiernos de la región están implementando diversas Políticas Activas del Mercado Laboral. Estas políticas apuntan a lograr la inserción laboral o reempleo a corto plazo de los trabajadores desempleados o personas vulnerables cuya inserción laboral es difícil. Los programas de formación cortos son la política activa más común en la región. Por lo general, operan en áreas urbanas y están dirigidas a los jóvenes más vulnerables o desfavorecidos (Ibarraran et al., 2014). Además, estos programas buscan incrementar el capital humano de sus beneficiarios como mecanismo clave para una rápida inserción al mercado laboral formal. Con este fin, ofrecen cursos de capacitación técnica de corta duración y experiencia laboral formal (a través de pasantías). Las rigurosas evaluaciones de impacto disponibles para algunos de estos programas revelan que, en el corto plazo, este tipo de programas no mejora las posibilidades de los beneficiarios de obtener un empleo, pero sí aumenta la probabilidad de conseguir un trabajo formal, es decir, un trabajo de mayor calidad, un trabajo decente (González Velosa Carolina, Ripani Laura, 2012). Dadas las características de los programas y los altos niveles de informalidad involucrados, especialmente en el caso de la población joven a la que se dirigen, este resultado es digno de mención. Por otro lado, las evaluaciones de los programas de formación profesional indican que el impacto de estos 
programas tiende a aumentar con el tiempo de ahí la importancia de medir su impacto más allá del corto plazo (dos años).

Durante la etapa de pandemia, los jóvenes expresan su preocupación por las consecuencias para la salud mental, el empleo, los ingresos disponibles y la educación, si bien la trayectoria de la pandemia varía según los países, la mayoría de los gobiernos de los países de la Organización para la Cooperación y el Desarrollo Económicos (OCDE) han implementado medidas de distanciamiento social, confinamiento y aislamiento social para contener la propagación del virus.

En este contexto, las organizaciones juveniles expresaron su mayor preocupación por el impacto de COVID-19 en el bienestar mental, el empleo, la pérdida de ingresos, las interrupciones en la educación, las relaciones familiares y las amistades, así como una limitación a las libertades individuales.

Según la OCDE el empleo temporal y mal remunerado en los sectores más afectados por la crisis (por ejemplo, restaurantes, hoteles y la industria recreativa) a menudo está en manos de jóvenes, que ahora se enfrentan a un mayor riesgo de pérdida de empleo e ingresos. El 35\% de los jóvenes (de 15 a 29 años) están empleados en trabajos mal pagados e inseguros, en comparación con el $15 \%$ de los empleados de mediana edad (30-50) y el $16 \%$ de los trabajadores mayores (de 51 años o más). La evidencia del inicio de la crisis demuestra que los jóvenes (15-24) fueron el grupo más afectado por el aumento del desempleo entre febrero y marzo. Ante una pérdida o una caída de los ingresos, los jóvenes tienen más probabilidades de caer en la pobreza, ya que tienen menos ahorros a los que recurrir. Además, como ilustran las crisis económicas anteriores, a los jóvenes que se gradúan en tiempos de crisis les resultará más difícil encontrar trabajos e ingresos decentes, lo que probablemente retrasará su camino hacia la independencia financiera. 
Más de una década después de la crisis financiera, la tasa de desempleo juvenil en los países de la OCDE se mantiene por encima de los niveles previos a la crisis, lo que demuestra los impactos duraderos que los choques económicos tienen no solo en la actual cohorte de jóvenes sino también en las generaciones futuras. El impacto económico causado por la crisis de COVID-19 también corre el riesgo de agravar las desigualdades existentes entre los jóvenes. Por ejemplo, durante la crisis financiera de 2007-2008, los jóvenes con bajos niveles de educación (por debajo de la secundaria superior) fueron los más afectados por el desempleo y la inactividad, que persistieron durante la lenta recuperación. Cifras recientes muestran que los jóvenes que no tienen más que educación secundaria inferior tienen tres veces más probabilidades de ser ninis en comparación con los que tienen un título universitario, lo que, a su vez, repercute en las perspectivas laborales futuras y las ganancias (OECD, 2020).

Según el documento, Perú: Evolución de los Indicadores de Empleo e Ingresos por Departamento, 2007-2018, fuente principal para estimar los indicadores económicos y sociales del país, elaborado a partir de los resultados de la Encuesta Nacional de Hogares realizada por el INEI (2018) se presenta las siguientes ilustraciones: 


\section{Figura 1.}

Perú: Participación de la población ocupada según grupos de edad y departamento, 2018 (Porcentaje).

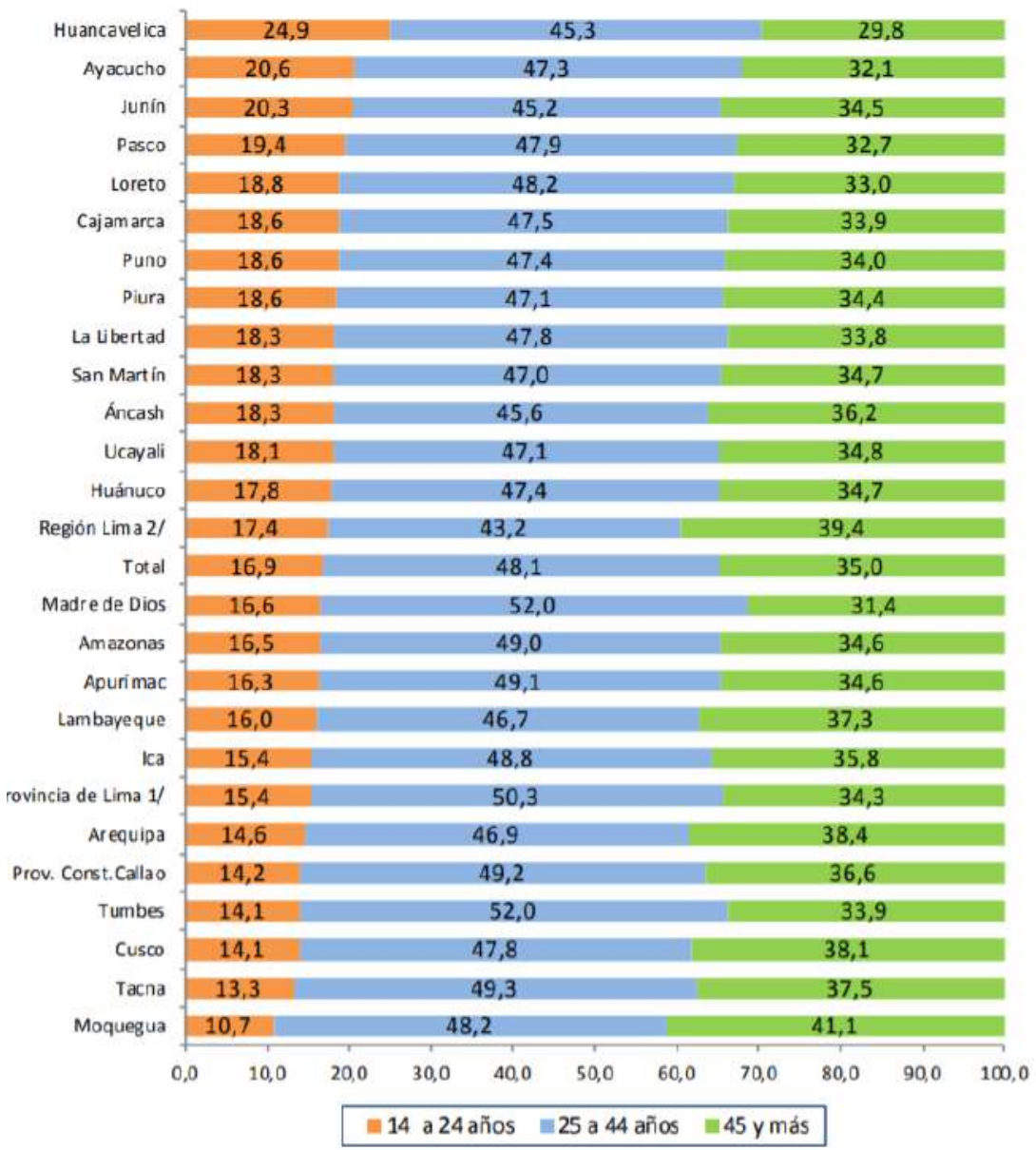

Fuente: Instituto Nacional de Estadística e Informática (INEI, 2018). 


\section{Figura 2.}

Perú: Tasa de empleo adecuado, subempleo y desempleo, según grupos de edad, 2017 y 2018 (Porcentaje).

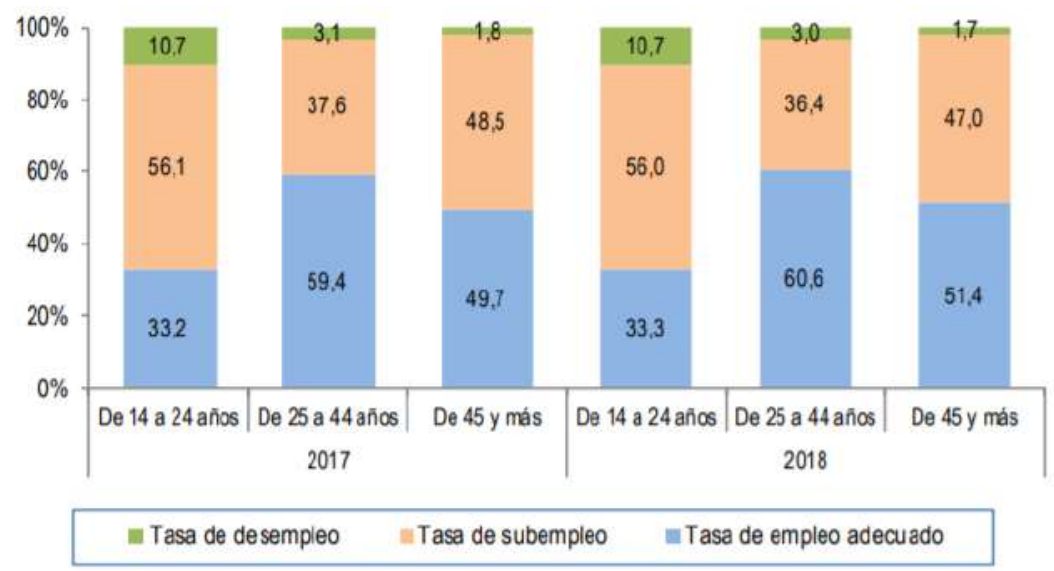

Fuente: Instituto Nacional de Estadística e Informática (INEI, 2018).

Entre abril y mayo de 2020, se realizó una encuesta en línea en 23 idiomas, la población de la encuesta comprendió a jóvenes de 112 países. Denominada encuesta mundial sobre los jóvenes y la pandemia del COVID-19. La siguiente ilustración presenta el porcentaje de todos los encuestados que trabajaban antes del inicio de la pandemia que: declararon que habían perdido su empleo desde el inicio del brote de COVID-19, o declararon que estaban trabajando, pero indicaron cero horas de trabajo diarias durante el brote.

El desglose por género y por ocupación incluye únicamente las observaciones de los encuestados de entre 18 y 29 años de edad (OIT, 2020). 


\section{Figura 3.}

Porcentaje de los encuestados que indicaron que habian dejado de trabajar tras el inicio de la pandemia.

Empleo perdido $\square$ Ninguna hora trabajada

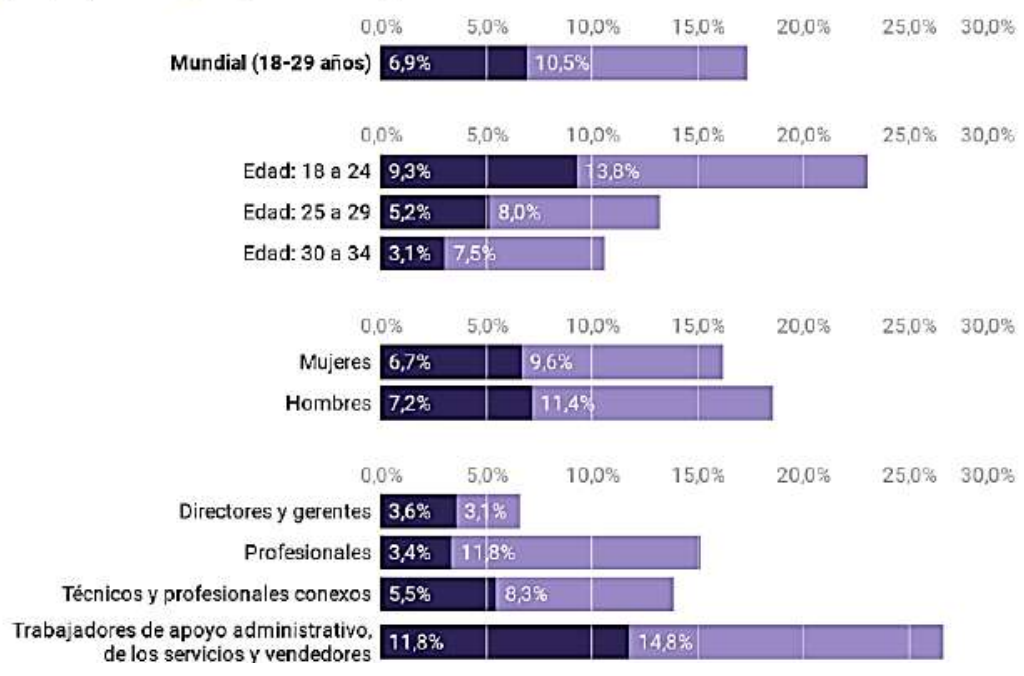

Fuente: (OIT, 2020).

La siguiente ilustración presenta el porcentaje de jóvenes (de 18 a 29 años) que indicaron una reducción de las horas trabajadas, de los ingresos y de la productividad (autoevaluada) en comparación con los niveles registrados antes de la pandemia de la COVID-19. 


\section{Figura 4.}

Tasa de desempleo por edades (\% sobre población activa, 2010 vs 2019).

\begin{tabular}{|c|c|c|c|}
\hline & Horas trabajadas & Ingresos & Productividad \\
\hline Mundial & $51 \%$ & $42 \%$ & $61 \%$ \\
\hline Género & Horas trabajadas & Ingresos & Productividad \\
\hline Mujeres & $50 \%$ & $38 \%$ & $64 \%$ \\
\hline Hombres & $52 \%$ & $46 \%$ & $59 \%$ \\
\hline Grupo de ingresos del pais & Horas trabajadas & Ingresos & Productividad \\
\hline Ingresos bajos & $67 \%$ & $48 \%$ & $72 \%$ \\
\hline Ingresos mediosbajos & $54 \%$ & $46 \%$ & 678 \\
\hline Ingresos mediosaltos & $50 \%$ & $43 \%$ & $57 \%$ \\
\hline Ingresos altos & $46 \%$ & $34 \%$ & 572 \\
\hline Sector público & Horas trabajadas & Ingresos & Productividad \\
\hline Directores y gerentes & $47 \%$ & $27 \%$ & $54 \%$ \\
\hline Profesionales & $52 \%$ & $24 \%$ & $62 \%$ \\
\hline Técnicos y profesionales conexos & $48 \%$ & $29 \%$ & $59 \%$ \\
\hline $\begin{array}{l}\text { Trabajadores de apoyo adm inistrativo, } \\
\text { de los servicios y vendedores }\end{array}$ & $43 \%$ & $23 \%$ & 548 \\
\hline Sector privado & Horas trabajadas & Ingresos & Productividad \\
\hline Directores y gerentes & $58 \%$ & $43 \%$ & $49 \%$ \\
\hline Profesionales & $55 \%$ & $55 \%$ & 5996 \\
\hline Técnicos y profesionales conexos & $48 \%$ & $54 \%$ & $56 \%$ \\
\hline $\begin{array}{l}\text { Trabajadores de a poyo adm inistrativo, } \\
\text { de los servicios y vendedores }\end{array}$ & $61 \%$ & $64 \%$ & $71 \%$ \\
\hline
\end{tabular}

Fuente: (OIT, 2020).

Por otro lado, Masclans \& Canals (2020), presenta la siguiente ilustración de la tasa de desempleo por edades, en países de Europa. 


\section{Figura 5.}

Tasa de desempleo por edades (\% sobre población activa, 2010 vs 2019).

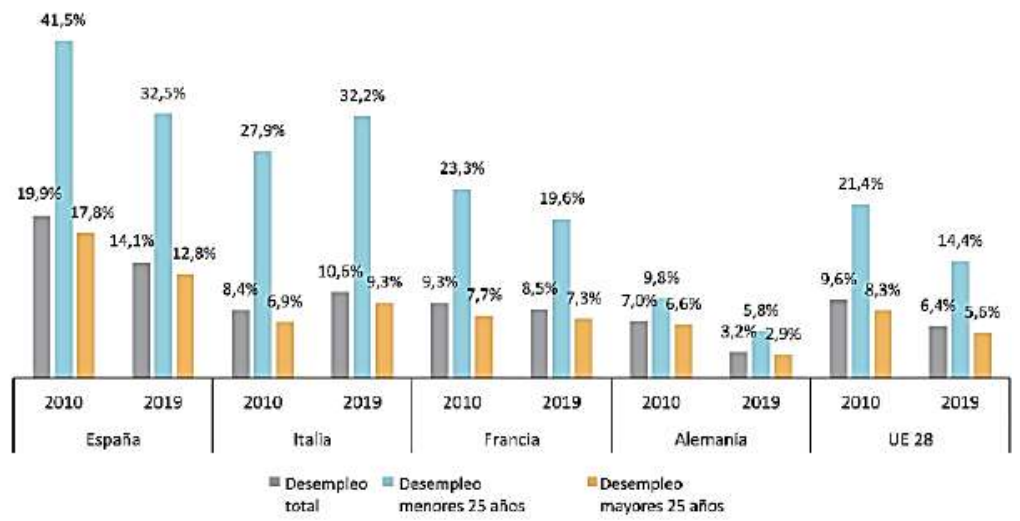

Fuente: (Masclans \& Canals, 2020).

Un estudio realizado se coloca a Perú como el país que más empleos han perdido por la pandemia del Coronavirus evaluación realizada por la Cámara de Comercio de Santiago de Chile (CCS) a los mercados latinoamericanos. Históricamente en el Perú, la tasa de desempleo sólo ha superado marginalmente el $10 \%$ de la población económicamente activa (PEA). Lo que da cuenta de que el problema principal del mercado laboral peruano no está representado por los desempleados, sino más bien la calidad del empleo. Hoy, la situación pandémica que nos ataña exhibe de manera precisa y golpea duramente a quienes menos se ocuparon de las deficiencias acarreadas.

Durante el segundo trimestre del año, de acuerdo a datos del Instituto Nacional de Estadística e Informática (INEI), existe una pérdida de más de 6 millones de empleos récord histórico de 8,8\%, pérdidas durante el período de confinamiento para reducir el contagio de la transmisión del virus. 


\section{Figura 6.}

Países que más porcentaje de empleo han perdido por la pandemia de COVID-19.

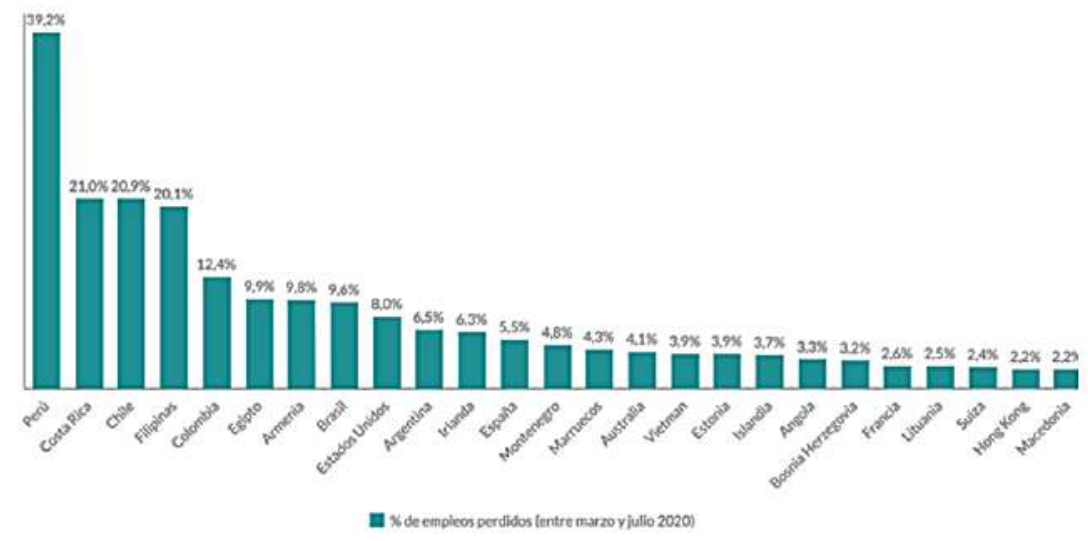

Fuente: Adaptado de Instituto Nacional de Estadística e Informática (Murialdo, 2020).

\section{Figura 7.}

Impacto inicial de la pandemia en el mercado laboral peruano.

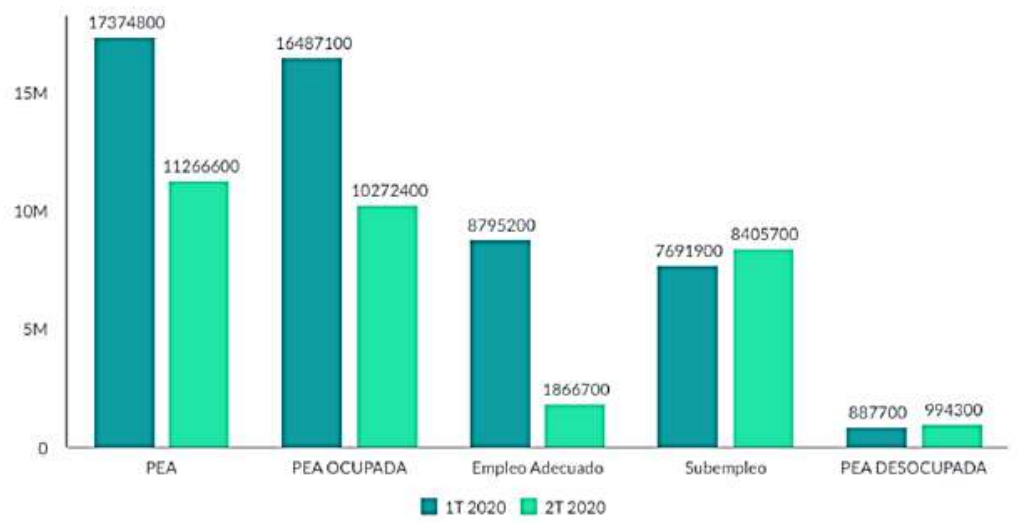

Fuente: Adaptado de Instituto Nacional de Estadística e Informática (Murialdo, 2020). 
En la ilustración se aprecia que, durante el segundo trimestre del 2020, 6214000 peruanos dejaron de formar parte de la población ocupada.

\section{LOS JÓVENES Y LA PANDEMIA}

Cuando se habla de los jóvenes durante la pandemia de COVID-19, la literatura existente intenta principalmente contextualizar la respuesta a la pandemia. En la vida de los jóvenes. La salud mental y el bienestar dominan la corriente de investigación a nivel nacional, estos enfoques toman una visión psicológica científica para explorar las tasas de depresión, insomnio y postraumáticos, trastorno de estrés entre los jóvenes, tanto como resultado de la propia pandemia y de las medidas de distanciamiento social implementadas para contener el virus. La estigmatización y rechazo social de la persona infectada o expuesta a la enfermedad puede ser un desencadenante de una peor adaptación (Yvette Terry Jordán, Niursy Bravo Hernández, Karla Sucet Elias Armas \& Carás, 2020). Según la OMS, la sociedad en general se enfrenta a un aumento probabilidad de estigma social para quienes dan positivo por COVID-19. Este estigma se agrava aún más para los jóvenes, dada la narrativa en curso como "super propagadores" del virus (Sy Lau et al., 2020).

La ansiedad con respecto a la economía es una amenaza para los jóvenes ahora y posiblemente en el futuro. En abril de 2020, "la tasa de desempleo juvenil aumentó en 5,5 puntos porcentuales hasta el $17,6 \%$, en comparación con un aumento del 2,7\% puntos para personas de 25 años o más" durante el período, además, la amenaza inminente de una inestabilidad económica sustancial se suma a los factores estresantes para los jóvenes que ya están ansiosos por los problemas económicos, eso puede no sentirse en la vida de la generación mayor (Franic \& Dodig-Curkovic, 2020).

Si bien muchas encuestas relacionadas con la juventud se realizan en el campo médico, el Jobs for Youth Initiative, junto con 
una serie de socios políticos, incluido el Foro Europeo de la Juventud, ha realizado una encuesta global sobre la juventud y COVID-19 con una perspectiva más holística. El informe de la encuesta recién publicado (Agosto de 2020) demuestra que los hallazgos clave globales luchan por el acceso igualitario a la educación, a pesar del deterioro de las oportunidades y perspectivas de empleo, la evaporación de espacios para la participación de los jóvenes y un creciente desafío de salud mental impulsado por la reactivación económica (Youth, 2020). En general, la literatura actual revela una creciente crisis de educación, empleo y salud mental que requerirá una inversión sustancial de política y trabajo juvenil urgente.

Los desarrollos de políticas en la revisión se exploran actualmente a escala global. Buscando la comparación de datos globales existentes con encuestas recientes realizadas a través de internet durante la pandemia, la OCDE y la ONU pudieron generar recomendaciones de políticas potenciales centradas en las necesidades específicas de jóvenes y niños. Los responsables de la formulación de políticas y las decisiones deben ser especialmente conscientes del componente de solidaridad intergeneracional al crear una respuesta de recuperación, especialmente porque los jóvenes y los niños probablemente enfrentarán más sobre los resultados a largo plazo de la pandemia.

La OCDE ha elaborado una serie de estudios, informes de políticas y medios que abordan los efectos de COVID-19 en la educación (OCDE, 2020a; OCDE, 2020b; OCDE, 2020c), comercio internacional y confianza pública en el gobierno. La culminación de estos trabajos y una encuesta a 90 organizaciones juveniles en 48 países del 7 al 20 de abril de 2020, forman la base de la política de la OCDE breve "Juventud y COVID-19: Respuesta, Recuperación y Resiliencia”. Este reporte mide los efectos desproporcionados que tiene la pandemia en los jóvenes e implicaciones probables para la solidaridad y la justicia intergeneracionales. Primero, la política breve 
establece las principales preocupaciones expresadas por los jóvenes según a las organizaciones juveniles. De manera abrumadora, las organizaciones juveniles declararon que los jóvenes expresaron mayores preocupaciones sobre la salud mental, el empleo y los ingresos en el sentido inmediato mientras que en a largo plazo, estas preocupaciones se dirigen hacia el bienestar futuro, cooperación y solidaridad (Miriam Allam \& Igrioglu, 2020). Desde la perspectiva de la OCDE, los gobiernos deberían ser conscientes del papel que desempeña la edad en las secuelas de manejar la crisis del COVID-19, de vital importancia es la necesidad de consulta intergeneracionales de jóvenes y organizaciones juveniles en los esfuerzos de recuperación y reconstrucción después de la pandemia.

Según la ONU hay tres principales canales en los que los niños y jóvenes se ven afectados por la crisis: la infección por virus en sí; los impactos socioeconómicos inmediatos de las medidas para detener transmisión del virus y acabar con la pandemia; y los posibles efectos a largo plazo del retraso en la implementación del Programa de Desarrollo Sostenible (objetivos) (UNICEF, 2020). Los niños vulnerables enfrentan mayores posibilidades de caer pobreza 0 pobreza extrema; aumenta la crisis del aprendizaje, a medida que las escuelas van cerrando en un intento de contener el virus, esto amenaza su salud y supervivencia; las dificultades económicas resultaron de una recesión económica que condujo a tasas de muerte y desnutrición creciente; y riesgo para su seguridad debido al bloqueo y refugio creciente de violencia y abuso. La propuesta de los gobiernos y los formuladores de políticas, buscan acciones inmediatas y sostenidas que incluyen: expandir las protecciones sociales y los programas que alcanzan a los más vulnerables (bonos); dar prioridad a los servicios centrados en el niño, con un enfoque particular en la equidad de acceso; y brindar apoyo a los padres y cuidadores, se espera que los resultados a largo plazo de la crisis, se contengan, bajo una buena 
decisión que vincula las respuestas a corto plazo de la política para proporcionar el apoyo adecuado en el presente.

\section{LOS JÓVENES VULNERABLES ANTE LA CRISIS DEL COVID-19}

La pandemia mundial también está teniendo un impacto sin precedentes en los sistemas educativos de todo el mundo, con consecuencias sociales de gran alcance. De acuerdo a UNESCO (2020), hasta el momento 191 países han implementado cierres de escuelas a nivel nacional o localizadas, lo que resulta en más $91 \%$ de los estudiantes matriculados, o 1.5 mil millones de personas, que no pueden ir a la escuela, colegios, institutos o universidades. Estos estudiantes enfrentan interrupciones en su educación de duración incierta, con diferentes niveles de métodos de entrega alternativos.

Estas interrupciones pueden afectar negativamente el aprendizaje, los cierres de las universidades tienen un efecto particularmente adverso en los más pobres, estudiantes sin acceso estable a internet en el hogar, peor aún la situación es especialmente grave para las niñas y mujeres jóvenes que están desproporcionadamente excluidas de la educación.

Para aliviar la situación, los gobiernos deberían asegurar que haya continuidad en el aprendizaje promoviendo soluciones de alta tecnología, baja tecnología y sin tecnología. Dado la gran brecha digital que existe, soluciones como la entrega contenido basado en texto a través de redes celulares en lugar de videoconferencias que se basan en Internet de alta velocidad, y materiales de aprendizaje a distancia en papel para familias sin ninguna conectividad digital, el acceso también debe ser considerado. Estudiantes con necesidades especiales, como los con discapacidades, requerirá atención adicional y el apoyo, ya que la educación virtual plantea desafíos particulares para ellos y sus familias. 
Los jóvenes vulnerables y marginados se encuentran en riesgo de COVID-19 y sus impactos. Jóvenes migrantes y refugiados, jóvenes que viven en zonas rurales, niñas adolescentes y mujeres jóvenes, jóvenes indígenas y de minorías étnicas, jóvenes con discapacidad, jóvenes que viven con VIH/SIDA, jóvenes de diferentes orientaciones sexuales e identidades de género y jóvenes sin hogar que ya experimentar desafíos en el acceso a los servicios de salud y protección social, jóvenes con problemas físicos o mentales las condiciones de salud también enfrentan un riesgo elevado en relación a COVID-19. Es posible que muchos jóvenes no tengan vivienda y por lo tanto no puede participar de manera segura en el distanciamiento social. La pandemia y la recesión económica puede alimentar aún más el estigma y la discriminación contra ciertos grupos de jóvenes, a su vez excluirlos del acceso a la atención médica y mantener sus medios de vida. Estos impactos dispares deberían informar la respuesta política integral a esta crisis.

Incluso antes de la llegada del COVID-19, había 621 millones de jóvenes (de 15 a 24 años) en todo el mundo sin educación, empleo o formación, son jovencitas las que constituyen la mayoría, tres veces más de probabilidad de desempleo que los adultos, y el $77 \%$ de ellos trabaja únicamente en la economía informal (Nations, 2020b). La recesión causada por la pandemia de coronavirus solo agravará estas vulnerabilidades. Muchos de los trabajos que se verán más afectados por la pandemia son predominantemente ocupados por trabajadores juveniles. Los jóvenes también tienden a ser los primeros en dejar de ir a sus trabajos, y con menos activos, redes y experiencia, no pueden enfrentar las dificultades de una crisis, menos encontrar un empleo. Estimaciones iniciales de las consecuencias del COVID-19 en la educación sugieren que, sin ninguna medida especial, los estudiantes podrían perder más de un año completo del aprendizaje, además, para muchos resulta imposible asumir una universidad de paga sin medios para costearlo (Kaffenberger, 2020). 
La pérdida de aprendizaje y la interrupción social pueden ser debilitantes y pueden conducir a la futura pérdida de productividad económica, aumento de la delincuencia, deterioro de la salud y otras inestabilidades. Crisis anteriores han demostrado que tales impactos tienden ser mucho más serio con los jóvenes que con los adultos. Un análisis del desastre, en estudios realizados entre 1981 y 2001 encontraron que el $62 \%$ de los jóvenes tenían afectados por el incidente, en comparación con el 39\% de los sobrevivientes adultos Asimismo, una revisión de las crisis financieras de 1980 a 2009 encontró que entre 15 y los jóvenes de 24 años tendían a verse más afectados que los grupos de mayor edad (Watson, P.J., Friedman, M.J. et al., 2003).

Los efectos son peores para las mujeres jóvenes, las menos educadas y jóvenes de minorías étnicas. Después de la crisis financiera mundial de 2008, los jóvenes el desempleo aumentó de 73 a 81 millones en todo el mundo. Los que eventualmente encontraron un trabajo a menudo enfrentan pérdidas sostenidas en ganancias futuras, así como pérdidas de productividad por no coincidir con los empleadores (Lundberg Mattias, 2020).

El desempleo y la informalidad en el Perú ya eran preocupantes y con la pandemia, éstas se han visto agravadas, sobre todo en el escenario juvenil, dada la poca experiencia acumulada de este sector como sus escasos años de educación (Beatty Egúsquiza Palacín, 2020). El trabajo como acción productiva y fuente de ingresos, derechos y bienestar social sigue siendo una aspiración y una deuda pendiente para un amplio sector de trabajadores peruanos. Un $55 \%$ de los trabajadores dependientes del sector empresarial privado labora en la informalidad laboral (sobre todo en el caso de las microempresas), esto es, sin acceso a la seguridad social ni a derechos laborales. Apenas el $6 \%$ de los asalariados privados formales se encuentra sindicalizado y puede negociar colectivamente. El resto trabaja al margen de una organización sindical que defienda sus 
intereses. El empleo formal creció significativamente en los últimos 10 años, sin embargo, solo 2 de cada 10 trabajadores peruanos accede a empleos decentes (Digno, 2020).

Para los estudiantes universitarios, una crisis puede obligarlos a abandonar sus estudios o rechazar la posibilidad de una mayor educación, lo que lleva a la falta de habilidades y preparación para el lugar de trabajo del futuro. Además, cuando la capacidad del gobierno para responder se debilita, los jóvenes a menudo tienen una mayor carga de los recortes de servicios públicos. Contrariamente a lo anterior a la crisis cuando el joven tenía una mayor sensación de bienestar en comparación con los adultos, muestra que muchos se sienten lo suficientemente preparados y lo suficientemente resilientes para recuperarse de las crisis, lo que tiene implicaciones preocupantes para su capacidad general prosperar en las actividades de la cuarta revolución industrial.

Los jóvenes son particularmente vulnerables dado que están atravesando una etapa de desarrollo sensible. La adolescencia es una fase crítica de la identidad formación. Los jóvenes tienden a desear oportunidades y propósitos, tanto de que se interrumpen en situaciones de crisis. Los cambios neurobiológicos en esta etapa pueden significar que son más propensos a comportamientos más riesgosos, turbulentas respuestas emocionales, ansiedad y depresión.

En la mayoría de los contextos socioculturales, los jóvenes tienen que enfrentarse a importantes hitos como graduación, incorporación a la fuerza laboral, matrimonio, votación, y exposición a sustancias tóxicas y alcohol, en una crisis o momentos de inestabilidad, los jóvenes se enfrentan a trastornos en todas estas áreas (Song et al., 2014).

Pueden experimentar menos autonomía, especialmente si se vuelven más dependiente económicamente de los padres o familiares. Cuando los hogares caen de repente en la pobreza, los jóvenes también 
pueden ser muy sensibles al estigma que trae y desarrollar una baja autoestima. Los cambios en el mercado laboral también pueden interferir con el desarrollo de aspiraciones positivas, identidad vocacional y un sentido de pertenencia a una sociedad. Incluso antes de la crisis de COVID-19, los jóvenes ya corrían un gran riesgo de dejar atrás su desarrollo de habilidades para la cuarta revolución industrial. Pueden haber estudiado para trabajos que se estaban volviendo obsoletos o con menos demanda. Para los que ingresar a la fuerza laboral, la transición al trabajo virtual puede significar perder las oportunidades para establecer contactos y relaciones con colegas, formación adecuada y desarrollo profesional temprano. Jóvenes menos resilientes que no pueden adaptarse a las condiciones de trabajo cambiantes se retrasarán en adquirir las habilidades críticas para el futuro del trabajo. El costo de no preparar a la juventud para hacer frente a los desafíos y reveses es, por tanto, alta.

\section{LA JUVENTUD, LA PANDEMIA Y EL PROBLEMA DE LA CUARTA REVOLUCIÓN INDUSTRIAL 4IR}

La Cuarta Revolución Industrial (4IR) es para transformar fundamentalmente la forma en que se organizan las sociedades modernas, y avances tecnológicos, especialmente en inteligencia artificial y automatización: puede provocar un grave desplazamiento de puestos de trabajo y escasez de habilidades. Se estima que para 2030, más de la mitad de los 1.600 millones del mundo los jóvenes no tendrán las habilidades o calificaciones necesarias para participar en la fuerza laboral mundial (Han \& goleman, daniel; boyatzis, Richard; Mckee, 2019b). Si los jóvenes no pueden adaptarse a la 4IR, las consecuencias serán nefastas no sólo para ellos como individuos sino también para sus familias, sus comunidades y la sociedad en general.

En 2018, Deloitte Global y Global Business Coalition for Education publicó un informe conjunto (Deloitte Global y Global Business, 2018) preparando la fuerza laboral del mañana para la Cuarta Revolución Industrial, exploró formas concretas en las que las 
empresas pueden ayudar a los jóvenes a prepararse para el futuro del trabajo, destacó cuatro categorías de las habilidades de las jóvenes necesarias para competir en el 4IR:

- Preparación de la fuerza laboral: fundamental para la entrada y éxito en el lugar de trabajo, desde la búsqueda inicial de empleo hasta mantener la continuidad.

- Habilidades blandas: atributos personales, habilidades sociales y habilidades de comunicación que apoyan las relaciones interpersonales relaciones e interacciones.

- Habilidades técnicas: conocimientos y capacidades para realizar tareas especializadas.

- Emprendimiento: conocimientos y habilidades que ayudan a crear y crear una oportunidad o idea en el lugar de trabajo.

El mundo ha cambiado fundamentalmente en 2020. En poco más de seis meses, la pandemia de COVID-19 ha producido la crisis mundial más grave desde la Segunda Guerra Mundial. Para abril de 2020, la Organización Internacional del Trabajo (OIT) estimó que el equivalente a 305 millones de empleos a tiempo completo perdido (International Labour Organization, 2020). Casi la mitad de la fuerza laboral mundial: los 1.500 millones de trabajadores en la economía informal, ahora se encuentran en una situación de extrema precariedad, teniendo poco acceso a la protección social básica y las redes de seguridad. Los cierres de escuelas y universidades en todo el mundo han afectado a más de 1500 millones de estudiantes, con pérdidas potenciales de más de un año completo del aprendizaje (Kaffenberger, 2020). Los costos económicos y sociales totales de la salud pública medidas como restricciones de movimiento, cierres de fronteras y órdenes de refugio en el hogar, no se conocerán durante muchos años, pero las estimaciones iniciales ya predicen un declive económico que rivalizará con la Gran Depresión (Jonathan Rothwell, 
2020). También ha quedado claro que el COVID-19 no es un gran ecualizador. El impacto de la pandemia es, y será, mucho más grave para los grupos marginados y comunidades. Es importante recordar que el COVID-19 se está desarrollando junto con otras crisis, barreras y choques visibles e "invisibles" en curso impactando a los jóvenes y al comercio en todo el mundo, incluyendo desastres naturales, enfermedades infecciosas como el ébola y el sarampión.

Restricciones de viaje e interrupciones en las cadenas de suministro globales mientras tanto, han hecho que sea extremadamente difícil para la salud y trabajadores responder a emergencias. La pandemia también se cruza con otras estructuras endémicas de la desigualdad y la opresión, incluido el racismo sistémico, el patriarcado, la riqueza disparidad y discriminación contra las personas con discapacidad, entre otras formas. Por ejemplo, en los EE. UU., la tasa de mortalidad de COVID-19 para negros estadounidenses son más del doble que cualquier otro grupo racial y étnico (Egbert, 2020). Las mujeres también soportarán una carga mayor que los hombres, ya que muchas de ellas están en los sectores laborales más afectados, como turismo y comercio minorista, al mismo tiempo que tiene que lidiar con el aumento de responsabilidades domésticas e incidencias de violencia doméstica.

A partir de la experiencia de crisis pasadas, el impacto en la juventud de COVID-19 será mucho más grave que en los adultos, con persistentes y a veces daño permanente a sus ingresos futuros y calidad de vida. Los jóvenes, por tanto, se enfrentan ahora a un futuro más incierto que nunca. Es posible que COVID-19 acelere el ritmo de automatización antes de que los jóvenes puedan prepararse adecuadamente para ello, la pandemia ha recordado al mundo cuán repentinamente puede aparecer una crisis, y que es imposible prepararse completamente para cada emergencia, si se desea vivir en prosperidad en el futuro, requerirá una mayor preparación y adaptabilidad a una variedad de situaciones de crisis. Por lo tanto, 
necesitamos una quinta categoría de habilidades de los jóvenes para el 4IR: La Resiliencia.

Esto abarcará las habilidades, conocimientos y actitudes que permitirán a la juventud no solo recuperarse de la adversidad, sino para "recuperarse" hacia un futuro mejor. Con la necesidad acrecentada por el COVID-19 y las crisis preexistentes, la resiliencia traerá grandes beneficios a los jóvenes, las empresas para las que trabajan, las comunidades en las que viven y sus economías nacionales. Cultivar la resiliencia de los jóvenes es una tarea crucial. Definida de manera simple, la resiliencia es la capacidad de recuperarse de las adversidades. De hecho, el concepto de resiliencia se utiliza con mayor frecuencia para discutir las respuestas de los sistemas. Una definición es que "la resiliencia puede definirse como la capacidad de un sistema dinámico para adaptarse con éxito a perturbaciones que amenazan el funcionamiento, la viabilidad o el desarrollo del sistema" (Ann S. Masten, 2013).

Uno de los factores que tiene mayor incidencia en los niveles de empleo es la educación. La lucha contra la pandemia y las medidas de confinamiento han intensificado el papel de la tecnología para impulsar el trabajo virtual desde el propio domicilio, exigiendo el desarrollo de competencias digitales, resulta importantes acortar la brecha en conocimientos tecnológicos y adecuarse a los nuevos perfiles profesionales.

Para cubrir la brecha de competencias y asegurar que se da respuesta a las necesidades futuras, las empresas necesitan que el sistema educativo impulse la mejora en la transmisión de conocimientos en las áreas tecnológicas, el desarrollo de las habilidades profesionales (soft skills) y el cultivo de las actitudes, que incluye también una reflexión sobre las humanidades (antropología, historia, literatura, etc.), impulsar el desarrollo de capacidades como el trabajo en equipo, la organización, la comunicación, el liderazgo o la iniciativa. Para ello sería importante una labor de orientación 
profesional temprana, que potencie el conocimiento y atractivo de las carreras técnicas, y una mayor presencia de docentes especializados en ciencias y matemáticas desde los primeros años escolares (Masclans \& Canals, 2020).

\section{PROBLEMÁTICA RESPECTO AL SECTOR TRABAJO FORMAL E INFORMAL}

En países con niveles de informalidad altos como el Perú, se enfrenta un desafío desproporcionado en respuesta a la pandemia de COVID-19. Los informales tienden a ser más afectados por los impactos del virus, ya que muchos no pueden dejar de funcionar, al menos no por un período prolongado, y por lo general carecen de protección social o esquemas institucionales de nivelación de ingresos, siendo difícil hacer cumplir las medidas o normas, incluidos los protocolos de seguridad o salud.

En el Perú, para la respuesta ante el COVID-19 se ha tenido que tomar en cuenta el hecho de que una gran cantidad de trabajadores tiene un empleo informal. En la etapa de emergencia, un desafío primordial consistió en diseñar mecanismos para transferir recursos a un sector que se caracteriza por una falta total de registro. Esta emergencia ha demostrado que el gobierno ha podido identificar tenuemente una lista de trabajadores que no tenían contacto previo con el Estado, iniciando un proceso que podría conducir a su formalización en el largo plazo.

Un factor importante que contribuyó fue el uso de nuevas tecnologías como medio para llegar a los trabajadores independientes. Esta también podría ser una oportunidad para el diálogo social tripartito sobre el uso de tecnologías para la formalización, así como para monitorear los caminos hacia la formalidad.

A mediano plazo, solo una fase de recuperación rica en empleo, respaldada por políticas e instituciones de empleo más sólidas, puede ayudar a reactivar las interrelaciones entre la 
producción, los ingresos y el consumo y, al mismo tiempo, proteger a los más vulnerables (OIT, 2020). Dada la dificultad de establecer una regla general para combinar los protocolos de seguridad, la reapertura de actividades y el impulso del gobierno de manera adecuada, una perspectiva microeconómica puede ser efectiva para complementar el enfoque macro de consolidación fiscal y/o inyección de liquidez en el sistema financiero. (S. Lee et al., 2020).

Luego del período de pandemia, se espera que la informalidad aumente en Perú, revirtiendo así la tendencia positiva observada en la década anterior. La transición a la formalidad vuelve a estar sobre el tapete, ya que Perú ha estado intentando reducir la informalidad durante muchas décadas. Dada la naturaleza de la informalidad en Perú, donde más de la mitad de la fuerza laboral produce una quinta parte del PIB, el problema real parece estar más relacionado con encontrar formas de promover la inclusión productiva de quienes se encuentran en la economía informal, un desafío que requiere un enfoque más integrado, acercarse a esta es otra característica que podría ser parte de una perspectiva microeconómica, para ser considerada en la fase de recuperación.

\section{PROGRAMAS JUVENILES ANTE EL COVID-19}

El Programa de Acción Mundial para los Jóvenes, llama a los gobiernos para garantizar que sus servicios cumplan con las necesidades de los jóvenes. En las circunstancias actuales, es especialmente importante que se escuche a los jóvenes junto con otras voces de la comunidad en el despliegue de intervenciones sanitarias y no sanitarias en respuesta al COVID-19.

El papel de los gobiernos, las organizaciones juveniles y los grupos comunitarios serán esenciales para desafiar la difusión de la desinformación en línea y para asegurar que la información de salud pública confiable sea diseminada. Los propios jóvenes también se están extendiendo información de salud pública en formas atractivas 
como videos para promover el lavado de manos eficaz o explicar cuán social el distanciamiento puede salvar vidas en sus comunidades.

Los jóvenes innovadores ya están respondiendo a la pandemia a través de proyectos con impacto social. Alrededor de mundo, los gobiernos y el sector privado se están asociando con los jóvenes para lanzar iniciativas que aprovechen los esfuerzos para apoyar a sus comunidades. Las políticas que permiten asociaciones con jóvenes en esta área pueden generar dividendos económicos y proporcionar una vía a los jóvenes para contribuir y demostrar su solidaridad en un tiempo de crisis.

A medida que se desarrolle la crisis, habrá una amplia gama de respuestas de políticas de juventud que se adaptan a contextos y necesidades específicos. Los países deberían invertir en proteger los derechos humanos, más allá del derecho a la salud, construir una sociedad más resiliente, incluso para los jóvenes.

\section{RESPUESTA SOCIAL ANTE LA CRISIS}

Medidas de protección social como pagos de transferencias en efectivo, ayuda por desempleo, licencia por enfermedad remunerada y acceso a la atención médica se están expandiendo en algunas jurisdicciones de forma temporal. Si tales medidas son para "no dejar uno detrás", es fundamental que tengan en cuenta la preocupaciones y necesidades particulares de los jóvenes, especialmente aquellos que no están incluidos en los desembolsos familiares o los sistemas de protección social basados en el empleo, como aquellos con trabajos informales.

Las políticas implementadas durante una crisis no solo deben salvaguardar los medios de vida y la seguridad financiera de los jóvenes a corto plazo, pero también sirven como base para la construcción de redes de seguridad social resilientes que reducen la vulnerabilidad de jóvenes a largo plazo. 
Ampliar el acceso a la atención médica ha sido fundamental aspecto de la respuesta COVID-19. En situaciones donde la cobertura sanitaria está vinculada al empleo, los jóvenes experimentan barreras de acceso ya que están desproporcionadamente desempleadas, trabajan en el sector informal o se encuentran entre los trabajadores pobres. Servicios dirigidos a las necesidades de las mujeres jóvenes y las niñas se han visto, en algunos casos, interrumpidas o se han desviado sus recursos. Es un derecho de todas las personas tener acceso y gozar de normas de salud alcanzables (Han \& goleman, daniel; boyatzis, Richard; Mckee, 2019a).

Como el virus puede afectar y ser transmitido por todos, la pandemia de COVID-19 también subraya el grado de cuya cobertura sanitaria universal es de suma importancia para la sociedad, asegurar el acceso efectivo a la atención médica para todos jóvenes durante este tiempo, barreras, como las que plantean el idioma o las instalaciones. Que son inaccesibles para las personas con discapacidad, deben ahora desmantelarse. La pandemia COVID-19 deja en claro la medida en que tales barreras no sólo negativamente afectan la salud de quienes están excluidos de la atención médica, pero también ponen en peligro la respuesta de salud pública requerida interrumpir la transmisión del virus.

La crisis en curso y las medidas de mitigación también tienen implicaciones para la salud mental. Mucha gente joven con problemas de salud mental está experimentando un deterioro de su estado de salud, aislamiento social prolongado y se espera que el estrés aumente la incidencia de jóvenes con problemas de salud mental (J. Lee, 2020).

Por tanto, la salud mental debería integrarse como parte de la respuesta sanitaria más amplia. Puede haber un plazo más largo impactos en la salud mental que actualmente se desconocen, qué proveedores de servicios públicos deberían ser sensibles. En muchos países, años de medidas de austeridad han dejaron los servicios públicos sin fondos suficientes y debilitadas respuestas para abordar 
eficazmente el COVID-19. Esto debería servir como lección en términos de la respuesta política a la pandemia. El COVID-19 probablemente estirará los gastos de gobiernos y profundizará la recesión y reducirá drásticamente los ingresos fiscales. Muchos gobiernos actualmente están realizando intervenciones extraordinarias para proteger sus economías. Se requieren inversiones similares para abordar los impactos sociales inmediatos de COVID-19, incluso en relación con la educación y el empleo para la juventud, así como los impactos a largo plazo en el desarrollo social. Ahora no es el momento de reducir las inversiones en juventud. La futura recuperación económica y el logro de los ODS dependerán de jóvenes capacitados y personas sanas que contribuyen con su trabajo, ideas y experiencia.

\section{LA AGENDA 2030, CUMPLIMIENTO DEL ODS 8 FRENTE A LA PANDEMIA}

El ODS 8 tiene como objetivo promover el crecimiento económico inclusivo y sostenible, el empleo y el trabajo decente para todos. El ODS 8 se esfuerza por impulsar a los gobiernos y a los responsables de la formulación de políticas a repensar y reinventar las políticas económicas y sociales para lograr el fin de la pobreza.

La pandemia de COVID-19 ha causado estragos en las economías de todos los países. Se estima que la economía global podría contraerse incluso peor que todas las crisis vistas antes. Si hay un retraso en el lanzamiento de una vacuna, las economías se contraerán aún más, causando inmensas dificultades a los más vulnerables y pondrán severas restricciones en el camino hacia la sostenibilidad.

Las consecuencias de la pandemia en curso son inimaginables. En particular, los sectores de servicios que requieren interacciones físicas como el comercio minorista, el ocio y el turismo son los sectores más afectados. Estos sectores representan casi el $25 \%$ de todos los puestos de trabajo. A medida que los ingresos se detengan o 
se vean afectados, el desempleo seguirá aumentando. La población activa se ha visto gravemente afectada y, con la interrupción de la actividad económica, su difícil situación solo aumentará. Esto tendrá efectos en cascada sobre la salud social y económica de los trabajadores. La actual crisis económica afectará gravemente al desarrollo sostenible. El impacto económico y social se experimenta incluso en los países ricos, ya que la mayoría de las personas no tienen la riqueza adecuada para vivir más allá de un cierto período. En algunos casos, no hay suficientes ahorros para contrarrestar el impacto monetario de la pandemia.

En países donde las leyes de protección laboral son laxas y donde las medidas preventivas no son una prioridad para el gobierno debido a los altos costos involucrados, el empeoramiento del impacto solo provocará ansiedad y estrés. La cantidad de personas y familias que se verán afectadas como resultado de esto es otra historia que el mundo tendrá que enfrentar. Necesitamos un desarrollo que satisfaga las necesidades del presente sin comprometer la capacidad de las generaciones futuras para satisfacer sus propias necesidades (Kuhlman \& Farrington, 2010).

En la pandemia, el tema del trabajo decente y el crecimiento económico ha estimulado a los gobiernos a poner sistemas y activar mecanismos de entrega, de modo que en el período intermedio se salven las vidas de las personas. Se está haciendo un esfuerzo para encontrar un camino intermedio entre el bloqueo y el inicio de actividades económicas de manera calibrada. Con suerte, esto nos encaminará hacia el logro de los objetivos del ODS 8.

La Agenda 2030 para el Desarrollo Sostenible debería orientar la respuesta y la recuperación de esta pandemia, y proporcionar el marco para desarrollar la resiliencia y cohesión social que el mundo necesitará para combatir el futuro. Las siguientes sugerencias mejorarían nuestra situación futura: 
- Proporcionar cobertura sanitaria universal, incluso para todos los jóvenes y garantizar que los sistemas de salud satisfagan eficazmente las necesidades de los jóvenes en tiempos de pandemia y durante toda la fase de recuperación, incluyendo promoción de salud pública, pruebas, tratamiento y prestación de servicios de salud mental.

- Promover información de salud pública precisa a través de diversas herramientas de comunicación y empoderar a los jóvenes para tomar decisiones basadas en evidencia con respecto su salud, al mismo tiempo que contribuye de manera proactiva a la prevención y mitigación.

- Mantener o aumentar el presupuesto y las inversiones en la salud, la educación y las competencias de los jóvenes: desarrollo, emprendimiento, oportunidades de empleo, mejora de condiciones de trabajo y mejora de su participación cívica.

- Adaptar la educación, a través de medios digitales y métodos no digitales desde la educación básica hasta la educación superior, para asegurar la adquisición continua de habilidades y aprendizaje, con especial atención a las necesidades de mujeres y niñas.

- Desarrollar políticas que lleguen a personas vulnerables y jóvenes marginados, incluidos los migrantes y refugiados, jóvenes que viven en zonas rurales, niñas adolescentes y mujeres jóvenes, minorías indígenas y étnicas jóvenes, jóvenes con discapacidad, jóvenes viviendo con VIH/SIDA, jóvenes de diferentes orientaciones sexuales e identidades de género, y jóvenes sin hogar.

- Fortalecer la capacidad nacional para recopilar y analizar y difundir datos desglosados por edad, género y otras características de la población, especialmente para abordar a los más marginados y vulnerables durante y después de esta pandemia. 
- Asegurar que los sistemas de protección social, incluidos todos los jóvenes, con especial atención a los que no están cubiertos por las medidas de protección social actual.

- Consultar e involucrar a los jóvenes en el desarrollo de intervenciones sanitarias, económicas y sociales en respuesta al COVID-19 y en su recuperación.

- Promover la innovación de los jóvenes para la prevención y tratamiento de COVID-19, y el manejo de sus impactos socioeconómicos corolarios.

- Respetar, promover y proteger los derechos humanos, en especial de los jóvenes, incluido el derecho a no discriminación.

\section{ESTRATEGIAS POLÍTICAS RESPECTO AL EMPLEO EN TIEMPOS DE PANDEMIA}

La emergencia sanitaria mundial COVID-19 y sus impactos económicos y sociales han alterado casi todos los aspectos de la vida de todos los grupos de la sociedad. Sin embargo, personas de diferentes edades están experimentando sus efectos de diferentes maneras. Para los jóvenes, y especialmente para los jóvenes vulnerables, la crisis del COVID-19 presenta riesgos considerables en los campos de la educación, el empleo, la salud mental y los ingresos disponibles. Además, si bien los jóvenes y las generaciones futuras soportarán gran parte de las consecuencias económicas y sociales a largo plazo de la crisis, su bienestar puede verse reemplazado por consideraciones económicas y de equidad a corto plazo. Para evitar exacerbar las desigualdades intergeneracionales e involucrar a los jóvenes en la construcción de la resiliencia social, los gobiernos deben anticipar el impacto de las medidas de mitigación y recuperación en los diferentes grupos de edad, mediante la aplicación de mecanismos de gobernanza efectivos. El resumen de políticas describe las medidas prácticas que los gobiernos pueden tomar para diseñar medidas de recuperación inclusivas y justas que no dejen a nadie atrás. 
A medida que los empleados regresan a sus lugares de trabajo después de que se levantan los cierres, es posible que no estén de acuerdo sobre las decisiones del gobierno, así como los empleadores, quienes están manejando la pandemia.

Las perspectivas de la cantidad y calidad del empleo se están deteriorando rápidamente. En tiempos de crisis, las Normas Internacionales del Trabajo proporcionan una base sólida para respuestas de política que se centran en el papel fundamental del trabajo decente, en el logro de una recuperación equitativa. Estas normas, adoptadas por representantes de gobiernos, trabajadores y organizaciones de empleadores, proporcionan un enfoque centrado en las personas para el crecimiento y el desarrollo, incluso activando palancas políticas que estimulen la demanda y protejan a los trabajadores y empresas. Las respuestas políticas deben centrarse en dos objetivos inmediatos: medidas de protección de la salud y apoyo económico tanto por el lado de la demanda como por el de la oferta. (International Labour Organization, 2020).

- Los trabajadores, empleadores y sus familias deben estar protegidos de los riesgos para la salud de COVID-19. Las medidas de protección en el lugar de trabajo y en todas las comunidades deben fortalecerse, requiriendo apoyo e inversión públicos a gran escala.

- Se deben realizar esfuerzos políticos coordinados, a gran escala y oportunos para proporcionar apoyo al empleo y a los ingresos y para estimular la economía y la demanda laboral. Estas medidas no solo protegen a las empresas y a los trabajadores del empleo inmediato y pérdidas de ingresos, pero también ayudan a prevenir una cadena de shocks de suministro (por ejemplo, pérdidas en capacidades de productividad) y shocks de demanda (por ejemplo, suprimir el consumo entre los trabajadores y sus familias) que podría conducir a una recesión económica prolongada. 
Se necesitan medidas proactivas, a gran escala e integradas en todos los ámbitos políticos para hacer impactos fuertes y sostenidos. Dado que la crisis está evolucionando rápidamente, un seguimiento cuidadoso de los efectos directos e indirectos de todas las intervenciones son cruciales para garantizar que las respuestas políticas relevantes.

El fomento de la confianza y el diálogo es fundamental para tomar medidas políticas eficaces, especialmente en tiempos de mayor tensión social y falta de confianza en las instituciones. El respeto y la confianza en los mecanismos de diálogo social crea una base sólida para construir al compromiso de empleadores y trabajadores en acción conjunta con los gobiernos. El diálogo social a nivel empresarial también es fundamental.

\section{CONCLUSIONES}

Antes de la aparición de COVID-19, los jóvenes (de 15 a 24 años) ya tenían tres veces más probabilidades de estar desempleados en comparación con los adultos, mientras que 126 millones de trabajadores jóvenes estaban en pobreza extrema y moderada en todo el mundo. Los trabajadores jóvenes tienen también más probabilidades de tener un empleo precario que otros grupos de edad. Mientras que alrededor del $77 \%$ de los jóvenes se estima que tienen un empleo informal a nivel mundial, este porcentaje es aún mayor para las mujeres jóvenes (OIT, 2020).

El aumento del desempleo como consecuencia del COVID19, superó el aumento de las tasas de desempleo tras la crisis financiera mundial de 2009. Basado en la experiencia de 2009, sin objetivos en política de intervención, es probable que los jóvenes se vean nuevamente desproporcionadamente afectados por una recesión global, con un mayor porcentaje de jóvenes desempleados en comparación a los adultos, y una aceptación más lenta del empleo por parte de los jóvenes durante la recuperación, es fundamental que las medidas para aliviar los impactos financieros en los hogares sean 
integrales y suficientes para cerrar la brecha resultante de la pérdida de ganancias.

La pandemia de COVID-19 ha provocado graves consecuencias económicas e impactos sociales en todo el mundo. Los jóvenes son particularmente vulnerables a las perturbaciones que la pandemia ha causado, y muchos ahora corren el riesgo de quedarse atrás en educación, oportunidades económicas, salud y bienestar durante una etapa crucial del desarrollo de su vida.

Los jóvenes tienen más probabilidades de estar desempleados o de estar contratados en trabajos precarios o arreglo oscuro laboral, por lo tanto, carecen de una protección social adecuada. Al mismo tiempo, los jóvenes están respondiendo a la crisis a través de promoción de la salud, voluntariado e innovación. Las personas jóvenes constituirán un elemento clave en una recuperación inclusiva y el logro del Desarrollo Sostenible Objetivos (ODS) durante esta década de acción. Sin embargo, la respuesta y la recuperación deben realizarse de manera que proteja los derechos humanos de todos los jóvenes.

El campo del trabajo con jóvenes está cambiando con una mayor necesidad de adaptación creativa a posibles incógnitas en las circunstancias de la pandemia. Lo que ha sido común a los casos recientes de adaptación, son los medios digitales de divulgación, que sin embargo pueden profundizar o abrir nuevas disparidades entre diferentes grupos de jóvenes.

Se necesita más empleo para el crecimiento sostenido del sistema. Las tasas de desempleo están aumentando a un ritmo mucho más rápido, mucho más con la explosión demográfica. La invención de la última tecnología ha vuelto a reducir la necesidad de más personas en el sistema, lo que una vez más ha llevado a la esfera del desempleo. El trabajo decente, como se menciona en los ODS, explica el trabajo que puede traer un buen estilo de vida para las personas en 
función de la demanda del mercado. Por un lado, cuando el costo de vida sube, los salarios no pueden cubrir la demanda, aparece el desequilibrio económico. Por lo tanto, es necesario un compromiso con las situaciones para satisfacer la calidad de vida y la demanda económica del sistema.

Esta crisis exige soluciones globales, solidaridad intergeneracional y soluciones políticas innovadoras e inclusivas, en este sistema competitivo y en constante cambio del mundo moderno, es muy necesario que encontremos la oportunidad de un mejor empleo en lugar de esperar a que el gobierno pague los gastos del individuo, por lo que es necesario preparar a los jóvenes para futuras emergencias en su adaptabilidad a una variedad de situaciones de crisis, por lo que se debe potenciar la habilidad de la resiliencia.

Teniendo en cuenta que la pandemia de COVID-19 aún continúa, existen muchos temas por explorar, los eruditos en la materia siguen proyectando sus ideas, y estas se encuentran cada vez más disponibles.

\section{REFERENCIAS BIBLIOGRÁFICAS}

Ann S. Masten. (2013). Global Perspectives on Resilience in Children and Youth - Masten - 2014 - Child Development Wiley Online Library. Society for Research in Child Development. https://srcd.onlinelibrary.wiley.com/doi/full/10.1111/cdev.12 205

Deloitte Global y Global Business. (2018). Connecting for a Resilient World | Deloitte Global. https://www2.deloitte.com/global/en/pages/aboutdeloitte/topics/combating-covid-19-with-resilience.html

Dicken, M. (2020). Youth work during a pandemic| Leatherhead Youth Project. Leatherhead Youth Project.

http://www.leatherheadyouthproject.com/news/youth-workduring-a-pandemic/ 
Egbert, A. (2020). COVID-19 deaths analyzed by race and ethnicity - APM Research Lab. APM Resechar Lab. https://www.apmresearchlab.org/covid/deaths-by-race

Franic, T., \& Dodig-Curkovic, K. (2020). Covid-19, child and adolescent mental health - Croatian (in)experience. In Irish Journal of Psychological Medicine (Vol. 37, Issue 3, pp. 214-217). Cambridge University Press. https://doi.org/10.1017/ipm.2020.55

Ginny Sprang, M. S. (2013). Posttraumatic stress disorder in parents and youth after health-related disasters - PubMed. National Library of Medicine. https://pubmed.ncbi.nlm.nih.gov/24618142/

González Velosa Carolina, Ripani Laura, R. S. D. (2012). ¿Cómo mejorar las oportunidades de inserción laboral de los jóvenes en América Latina? Banco Interamericano de Desarrollo.

https://publications.iadb.org/es/publicacion/16596/comomejorar-las-oportunidades-de-insercion-laboral-de-losjovenes-en-america

Han, E. S., \& goleman, daniel; boyatzis, Richard; Mckee, A. (2019a). El derecho al disfrute del mas alto nivel posible de salud. Naciones Unidas, 53(9), 1689-1699.

Han, E. S., \& goleman, daniel; boyatzis, Richard; Mckee, A. (2019b). The learning generation. Journal of Chemical Information and Modeling, 53(9), 1689-1699.

Ibarraran, P., Ripani, L., Taboada, B., Villa, J. M., \& Garcia, B. (2014). Life skills, employability and training for disadvantaged youth: Evidence from a randomized evaluation design. IZA Journal of Labor and Development, 3(1), 1-24. https://doi.org/10.1186/2193-9020-3-10

INEI. (2018). Perú : Evolución de los Indicadores de Empleo e Ingresos por Departamentos ,. INEI, 2001-2009.

International Labour Organization. (2020). Global impact and policy recommendations (COVID-19 and the world of work). ILO 
Monitor First Edition, March, 1-15. http://www.ilo.org/global/topics/coronavirus/impacts-andresponses/lang--en/index.htm

Jonathan Rothwell, S. D. (2020). How misinformation is distorting COVID policies and behaviors. Brookings.

https://www.brookings.edu/research/how-misinformation-isdistorting-covid-policies-and-behaviors/

Kaffenberger, M. (2020). Modeling the Long-Run Learning Impact of the COVID-19 Learning Shock: Actions to (More Than) Mitigate Loss | RISE Programme. RISE.

https://riseprogramme.org/publications/modeling-long-runlearning-impact-covid-19-learning-shock-actions-moremitigate-loss

Kuhlman, T., \& Farrington, J. (2010). What is sustainability? In Sustainability (Vol. 2, Issue 11, pp. 3436-3448). https://doi.org/10.3390/su2113436

Lee, J. (2020). Mental health effects of school closures during COVID-19. The Lancet Child and Adolescent Health, 4(6), 421. https://doi.org/10.1016/S2352-4642(20)30109-7

Lee, S., Vanhuynegmen, P., \& Chacaltana, J. (2020). ¿Respuesta rápida a la covid-19 en un contexto de alta informalidad? El caso del Perú. Organización Mundial Del Trabajo, 1-8. https://iep.org.pe/wp-content/uploads/2020/04/Informe-OPAbril-2020-5-Impacto-en-la-economía-del-Covid-19v2.pdf\%0Ahttp://www.ilo.org/wcmsp5/groups/public/--ed_emp/documents/publication/wcms_747776.pdf

Lundberg Mattias, W. A. (2020). Children and Youth in Crisis : Protecting and Promoting Human Development in Times of Economic Shocks. Open Knowledge Repository. https://openknowledge.worldbank.org/handle/10986/9374

Masclans, R., \& Canals, J. (2020). María luisa blázquez roger masclans jordi canals. Las Competencias Profesionales Del Futuro: Un Diagnóstico y Un Plan de Acción Para Promover El Empleo Juvenil Después de La COVID-19, 90. 
https://doi.org/dx.doi.org/10.15581/018.ST-548

Miriam Allam, A. M., \& Igrioglu, G. (2020). What steps are youth organisations taking to mitigate the COVID-19 Crisis? $O C D E$. OCDE. https://www.oecd.org/fr/gov/what-steps-areyouth-organisations-taking-to-mitigate-the-covid-19crisis.htm

Murialdo, M. (2020). Desempleo por Pandemia de Coronavirus en el Perú| by Melisa Murialdo | Medium. MELISA MURIALDO.

https://melisamurialdo.medium.com/desempleo-porpandemia-de-coronavirus-en-el-perú-f8dfe652b023

Naciones Unidas/CEPAL. (2019). La Agenda 2030 y los Objetivos de Desarrollo Sostenible: una oportunidad para América Latina y el Caribe. Objetivos, metas e indicadores mundiales. In Publicación de las Naciones Unidas.

Nations, U. (2020a). GNUDS | Resumen de políticas: El impacto de COVID-19 en los niños. Grupo de Las Naciones Unidas Para El Desarrollo Sostenible. https://unsdg.un.org/es/resources/resumen-de-politicas-elimpacto-de-covid-19-en-los-ninos

Nations, U. (2020b). Protecting and mobilizing youth in COVID-19 responses | Department of Economic and Social Affairs. Naciones Unidas.

https://www.un.org/development/desa/dpad/publication/undesa-policy-brief-67-protecting-and-mobilizing-youth-inCovid-19-responses/

OECD. (2020). Education responses to COVID-19: Embracing digital learning and online collaboration. OECD. http://www.oecd.org/coronavirus/policyresponses/education-responses-to-covid-19-embracingdigital-learning-and-online-collaboration-d75eb0e8/

OIT. (2020). Efectos en los empleos, la educación, los derechos y el bienestar mental. Los Jovenes y La COVID-19.

Song, S., Sikorski, J., Doll, B., \& Sikorski, M. (2014). Resilience 
Interventions for Youth in Diverse Populations. Resilience Interventions for Youth ..., 203-215. https://doi.org/10.1007/978-1-4939-0542-3

Sy Lau, M., Grenfell, B., Thomas, M., Bryan, M., Nelson, K., \& Lopman, B. (2020). Characterizing super-spreading events and age-specific infectiousness of SARS-CoV-2 transmission in Georgia, USA. MedRxiv, 2020.06.20.20130476.

www.pnas.org/cgi/doi/10.1073/pnas.XXXXXXXXXX

Verónica Alaimo, Alvaro Altamirano, Daniela Dborkin, A. I. (2018). Subsidizing Informality?: Non-contributory Public Spending in Latin America and the Caribbean | Publications. InterAmerican Development Bank.

https://publications.iadb.org/publications/english/document/S ubsidizing-Informality-Non-contributory-Public-Spendingin-Latin-America-and-the-Caribbean.pdf

Watson, P.J., Friedman, M.J., G., L.E., Ruzek, J.I., Norris, F. H., \& Ritchie, E. . (2003). Potomac Behavioral Solutions. Trauma and Disaster: Responses and Management, Washington, DC, American Psychiatric.

https://www.pbshealthcare.com/\#newofficespace

Youth, D. J. for. (2020). Decent Jobs for Youth. Decent Jobs for Youth. https://www.decentjobsforyouth.org/ 